Original Research Article

\title{
Audit of prescriptions from the department of general medicine based on the WHO core prescribing indicators at Sapthagiri hospital, Bangalore
}

\author{
Navya Teja K.*, Piyali Hazra, L. Padma
}

Department of Pharmacology, Sapthagiri Institute of Medical Sciences and Research Centre, Bangalore, Karnataka, India

Received: 16 September 2019 Accepted: 17 October 2019

*Correspondence to:

Dr. Navya Teja K.,

Email:

navyatejakims@gmail.com

Copyright: (C) the author(s), publisher and licensee Medip Academy. This is an openaccess article distributed under the terms of the Creative Commons Attribution NonCommercial License, which permits unrestricted noncommercial use, distribution, and reproduction in any medium, provided the original work is properly cited.

\begin{abstract}
Background: As medical students start their clinical training, more effort goes in the direction of proper diagnosis and appropriate methods of treatment, leading to improper training in prescription writing causing prescription errors. Physicians should also be encouraged to prescribe unbranded generic medicines which are available at a cheaper price with a comparable bioavailability of drugs and not have a misconception of being less efficacious.

Methods: A cross-sectional observational study was carried out over a period of 2 months (September to October 2018). Around 256 prescriptions were randomly collected from general medicine out-patient department. Informed consent was obtained verbally, and confidentiality assured. The collected data was analyzed as per descriptive statistics and compared with the derived standard values for WHO prescribing indicators.

Results: The analyzed data showed an average of $2.23 \pm 1.03$ drugs per prescription. $23 \%$ of the prescriptions had at least one drug prescribed by generic name, $25 \%$ of prescriptions contained an antibiotic and $31 \%$ of prescriptions had an injection. The percentage of drugs prescribed from NLEM (National list of Essential Medicines) was only 57\% as compared to the recommended $100 \%$. Additional only $22.4 \%$ of the total number of FDCs prescribed were from NLEM.

Conclusions: The average number of drugs per prescription was slightly high, indicating polypharmacy. Brand name prescribing dominates as doctors are still reluctant to use generic names being doubtful of the efficacy. Regular prescription audit with reporting might help to bring awareness among doctors to follow the recommended guidelines and minimize prescription errors.
\end{abstract}

Keywords: Polypharmacy, Rational prescribing, World health organization core prescribing indicators

\section{INTRODUCTION}

WHO defines Rational prescribing as "Medicine use is rational when patients receive the appropriate medicines, in doses that meet their own individual requirements, for an adequate period of time, and at the lowest cost both to them and the community." Irrational use of medicines is when one or more of these conditions is not met. ${ }^{1}$

As the medical students start their clinical training, more effort goes in the direction of proper diagnosis and appropriate methods of treatment leading to improper training in prescription writing causing prescription errors. If unchecked, these might land up sometime in the court of law although the prescriber was with good intention. $^{2}$

Essential drug lists are designed based on the healthcare needs of the majority, and since these are available at all times in adequate amounts and in appropriate dosage forms, prescribing drugs from these lists would not only be economical to the patient, but also promote rational prescribing. $^{3}$ 
Mixing of many drugs in a single prescription, known as polypharmacy, poses an increased risk of Adverse Drug Reactions (ADRs) and drug-drug interactions, testing the knowledge of the prescriber.

Nevertheless, rational fixed drug combinations are not considered as polypharmacy. ${ }^{4}$ Physicians should also be encouraged to prescribe unbranded generic medicines which are available at a cheaper price with a comparable bioavailability of drugs and not have the misconception of being less efficacious. ${ }^{5}$

\section{The WHO core prescribing indicators include}

- Average number of drugs prescribed per encounter.

- Percentage of drugs prescribed by generic name.

- Percentage of patient encounters with an antibiotic prescribed.

- Percentage of patient encounters with an injection prescribed

- Percentage of drugs prescribed from the national EDL or formulary. ${ }^{6}$

Undertaking this study to audit the prescriptions of OPD from the Department of General Medicine of Hospital would help to determine the quality of prescriptions against the standard recommended WHO core prescribing indicators, as this has not been done before.

Objective was assessment of prescriptions based on the WHO core prescribing indicators collected from the Department of General Medicine at Sapthagiri Hospital, Bangalore.

\section{METHODS}

A cross-sectional observational study was carried out over a period of 2 months (September 2018 to October 2018), at Sapthagiri Institute of Medical Sciences and Research Centre, Bangalore. After obtaining ethical clearance from the Institutional ethics committee, around 256 prescriptions were randomly collected, using convenience sampling method, from the general medicine out-patient department during the study period. Prescriptions from patients of either sex more than 18 years of age were collected for analysis. Informed consent from the patients was obtained verbally, and confidentiality assured.

\section{Statistical analysis}

The collected data, comprising of the demographic details like age and gender, along with the prescribed medications, were entered into Microsoft Excel 2013 for analysis. Fixed Dose Combinations (FDCs) were considered as a single drug. Analysis was done as per descriptive statistics. The obtained results were compared with the derived standard values for WHO prescribing indicators (Table 1$)^{7}$
Table 1: Derived standard values for the WHO prescribing indicators.

\begin{tabular}{|c|c|}
\hline Indicators & $\begin{array}{l}\text { Standard } \\
\text { values }\end{array}$ \\
\hline 1. Average number of drugs per encounte & $1.6-1.8$ \\
\hline $\begin{array}{l}\text { 2. Percentage of encounters with an } \\
\text { antibiotic prescribed. }\end{array}$ & $20.0-26.8$ \\
\hline $\begin{array}{l}\text { 3. Percentage of encounters with an } \\
\text { injection prescribed. }\end{array}$ & $13.4-24.1$ \\
\hline $\begin{array}{l}\text { 4. Percentage of drugs prescribed by } \\
\text { generic name. }\end{array}$ & 100.0 \\
\hline $\begin{array}{l}\text { 5. Percentage of drugs prescribed from } \\
\text { the essential drug list/formulary. }\end{array}$ & 100.0 \\
\hline
\end{tabular}

\section{RESULTS}

Out of 256 patient encounters assessed during the study period (September to October 2018), 132 (51.6\%) were female patients and $124(48.4 \%)$ were males. The age of patients ranged from the youngest being 18 years and the oldest being 89 years, with a mean age of 45 years as depicted in Table 2.

Table 2: Demographic features of patients who participated in the study.

\begin{tabular}{|lll|}
\hline $\begin{array}{l}\text { Characteristics } \\
\text { Age (years) }\end{array}$ & Frequency & Percentage $(\%)$ \\
\hline $15-20$ & 7 & 2.73 \\
\hline $21-30$ & 48 & 18.75 \\
\hline $31-40$ & 63 & 24.62 \\
\hline $41-50$ & 56 & 21.87 \\
\hline $51-60$ & 38 & 14.84 \\
\hline $61-70$ & 28 & 10.94 \\
\hline $71-80$ & 10 & 3.91 \\
\hline $81-90$ & 6 & 2.34 \\
\hline Gender & & \\
\hline Male & 124 & 48.4 \\
\hline Female & 132 & 51.6 \\
\hline
\end{tabular}

In 13 out of the 256 encounters, the patient was not prescribed any new drug. Reasons for the same being requirement of investigations for further treatment, advising only home remedies or life-style modifications and sometimes the encounter being just a follow-up requiring no further medications (Figure 1).

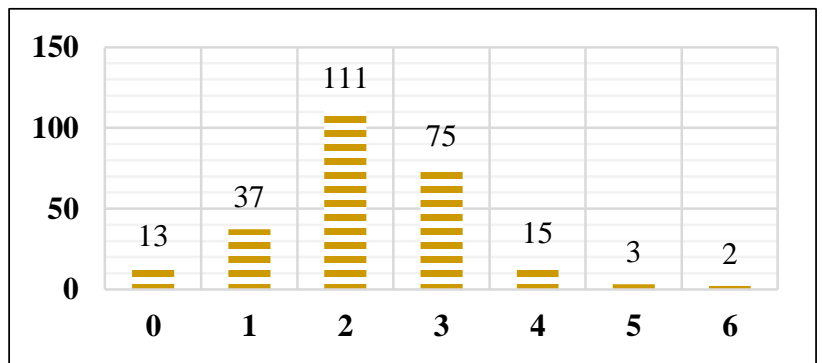

Figure 1: Number of drugs per prescription. 
The analyzed data showed a total of 571 drugs being prescribed in 256 patient encounters, depicting an average of $2.23 \pm 1.03$ drugs per prescription. Maximum number of prescriptions $(43.36 \%)$ contained 2 drugs and only $7.81 \%$ of prescriptions contained 4 or more number of drugs (Figure 1).

Around $25 \%$ of prescriptions (64 out of 256) contained an antibiotic as depicted in (Figure 2).

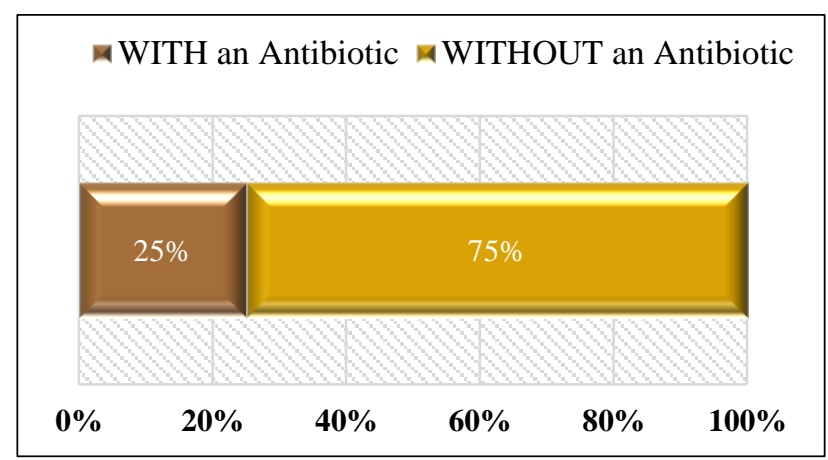

Figure 2: Percentage of encounters with an antibiotic prescribed.

Approximately $20.3 \%$ of prescriptions (52 out of 256) had at least one drug prescribed by generic name, corresponding to only $10.5 \%$ of the total number of drugs (60 out of 571) that were prescribed in 256 encounters (Figure 3).

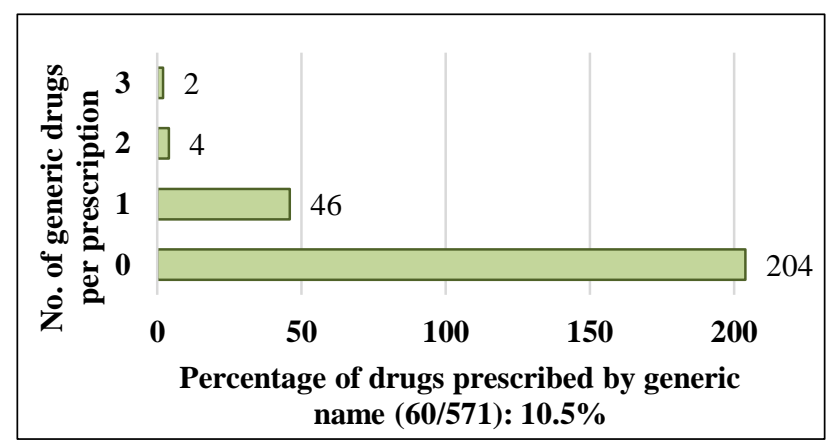

Figure 3: Number of drugs prescribed by generic name.

$30.86 \%$ of prescriptions (79 out of 256) contained at least one injectable preparation, and the remaining 177 prescriptions had only oral preparations. Of the 79 prescriptions, 68 of them had a single injection and 11 of then contained two injections, accounting for $15.76 \%$ of total drugs (90 out of 571) to be injectables (Figure 4). In this study, $74.22 \%$ of prescriptions (190 out of 256) contained at least one drug from the NLEM (National List of Essential Medicines), and of the 571 drugs prescribed in 256 encounters only $325(57 \%)$ were present in the NLEM (Figure 5).

Additional only 49 (22.4\%) FDCs, out of 219 FDCs prescribed were from NLEM (Figure 6).

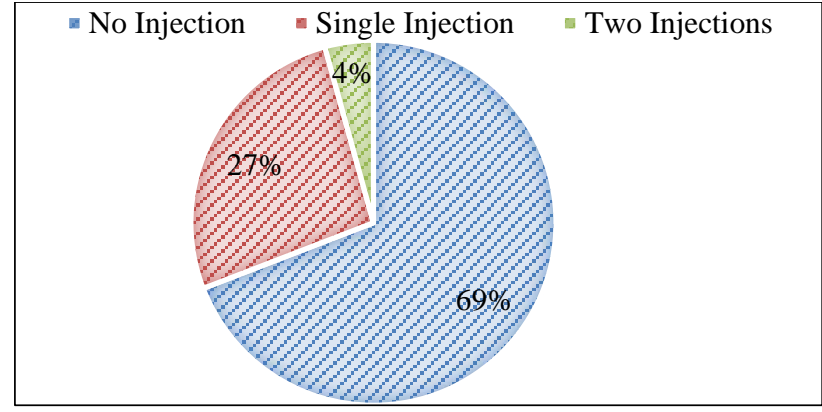

Figure 4: Percentage of encounters with an injection prescribed.

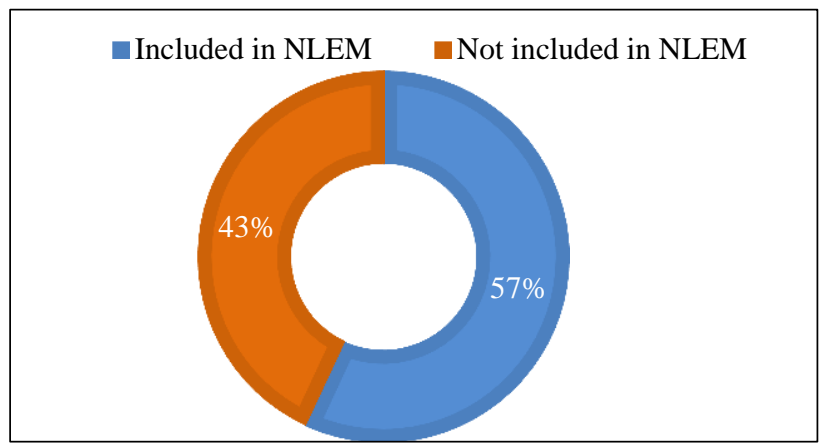

Figure 5: Percentage of drugs prescribed from NLEM.

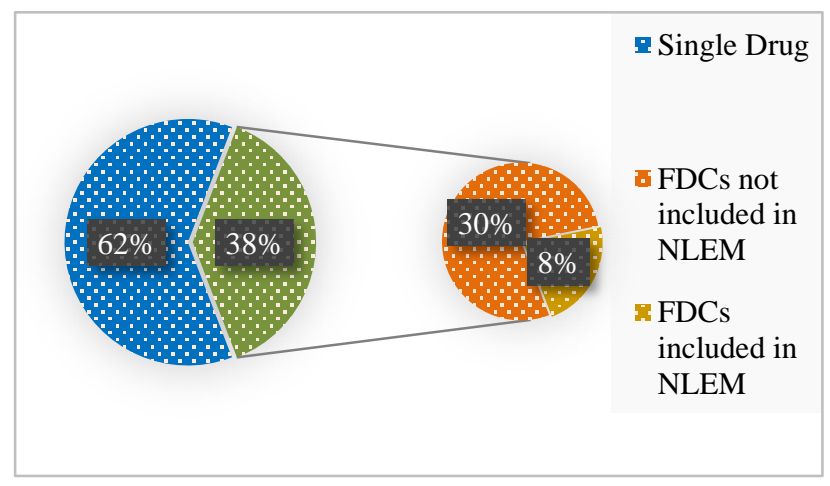

Figure 6: Percentage of FDCs prescribed.

\section{DISCUSSION}

A prescription is a significant and effective way of implementing intervention by the physician for the health of patients. The main objective of the current study was to analyse the current trends in prescribing drugs, followed by the practitioners, and comparing it with the standard WHO prescribing indicators. Polypharmacy is commonly encountered in elderly patients who have multiple comorbid conditions. Hospitalization also frequently causes patients to end up taking multiple medicines. However, lack of knowledge of drug-drug and drug-food interactions can pose a risk of increased adverse effects or even therapeutic failure. ${ }^{8}$ Polypharmacy is a major issue seen especially with private practitioners as compared to government doctors, as observed in a study conducted by Ahsan et al. ${ }^{9}$ This study shows an average of $2.23 \pm 1.03$ 
drugs per prescription, indicating moderate polypharmacy. Creating an awareness about the importance of antibiotic stewardship and implementing a rigid hospital antibiotic policy might help in combating the problem of injudicious use of antibiotics leading to antimicrobial resistance. In this study, $25 \%$ of prescriptions contained an antibiotic, which is comparable to another study conducted by Chandelkar et al, where $31.8 \%$ of prescriptions contained an antibiotic. ${ }^{10}$

Prescribing the drugs from the essential drug list (NLEM) would be more pocket friendly to the patients, as these are designed to cover maximum illnesses prevalent in the population. WHO recommends $100 \%$ of drugs to be prescribed from such a list. However, this study showed that only $57 \%$ were from NLEM, a similar result $(52.86 \%)$ seen in a study conducted by Saha et al., so a periodic update on the NLEM and its importance would help the physicians prescribe more drugs from the NLEM and avoid unnecessary economic burden. ${ }^{11}$

Most of the physicians are still apprehensive to prescribe unbranded generic drugs as they are doubtful of their safety and efficacy, resulting in only $10.5 \%$ of drugs that were prescribed by generic names in this study. Awareness should be created about the mandatory BA/BE studies conducted for the generic drugs, to remove this misconception from the prescribers and promote judicious use of generic drugs. This would also help in avoiding usage of irrational FDCs and restricting the prescriber to stick to FDCs from NLEM. ${ }^{12}$ In this study, only $22.4 \%$ of FDCs were from NLEM, indicating extensive use of irrational FDCs.

\section{CONCLUSION}

The average number of drugs per prescription was slightly high, indicating moderate polypharmacy. Brand name prescribing dominates as doctors are still reluctant to use generic names being doubtful of the efficacy. Physicians should be encouraged to prescribe from NLEM, which would not only help them to avoid irrational prescribing but also reduce economic burden for the patients. Conducting regular prescription audits with periodic reporting might help to bring awareness among doctors to follow the recommended guidelines and minimize prescription errors and irrational prescribing.

\section{ACKNOWLEDGEMENTS}

Authors would like to acknowledge the faculty of Department of General Medicine, Sapthagiri Institute of Medical Sciences and Research Centre, Bangalore, for their help and co-operation for data collection.

\section{Funding: No funding sources} Conflict of interest: None declared

Ethical approval: The study was approved by the Institutional Ethics Committee

\section{REFERENCES}

1. WHO: The pursuit of responsible use of medicines: sharing and learning from country experiences? World Health Organization; 2012. p 2. Available at http://www.who.int/medicines/areas/rational_use/en/ Accessed 13 August 2018.

2. WHO: De Vries TPG, Henning RH, Hogerzeil HV, Fresle DA, Policy M, Guide to good prescribing: a practical manual. 1994; p 1. Available at http://apps.who.int/medicinedocs/en/d/Jwhozip23e/2. html Accessed 13 August 2018.

3. Gopalakrishnan S, Ganeshkumar P, Katta A. Assessment of prescribing practices among urban and rural general practitioners in Tamil Nadu. Ind $\mathbf{J}$ Pharmacol. 2013;45(3):252.

4. Aravamuthan A, Arputhavanan M, Subramaniam K. Assessment of current prescribing practices using World Health Organization core drug use and complementary indicators in selected rural community pharmacies in Southern India. J Pharma Policy Prac. 2017;10(1):1.

5. Mathew P. Generic drugs: Review and experiences from South India. J Family Medi Pri Care. 2015;4(3):319.

6. World Health Organization: How to Investigate Drug Use in Health Facilities: Selected Drug Use Indicators - EDM Research Series. Available at http://apps.who.int/medicinedocs/en/d/Js2289e/ Accessed 13 August 2018.

7. Isha A, Ross-Degnan D, Quick J, Laing R, Mabadeje A. The development of standard values for the WHO drug use prescribing indicators. Available at: http://archives.who.int/prduc2004/rducd/ICIUM_Post ers/1a2_txt.htm. Accessed 13 August 2018.

8. Rambhade S, Chakarborty A, Shrivastava A, Patil UK, Rambhade A. A survey on polypharmacy and use of inappropriate medications. Toxicol Int. 2012;19(1):68.

9. Ahsan M, Shaifali I, Mallick AK, Singh HK, Verma S, Shekhar A. Prescription auditing based on World Health Organization (WHO) prescribing indicators in a teaching hospital in North India. Int $\mathrm{J}$ Med Res Rev. 2016;4(10):1847-52.

10. Chandelkar UK, Rataboli PV. A study of drug prescribing pattern using WHO prescribing indicators in the state of Goa, India. Int J Basic Clin Pharmacol. 2014;3(6):1057-61.

11. Saha A, Bhattacharjya H, Sengupta B, Debbarma R. Prescription audit in outpatient department of a teaching hospital of North East, India. Int J Res Medi Sci. 2018;6(4):1241.

12. Mathew P. Generic drugs: Review and experiences from South India. J Family Medi Pri Care. 2015;4(3):319.

Cite this article as: Teja KN, Hazra P, Padma L. Audit of prescriptions from the department of general medicine based on the WHO core prescribing indicators at Sapthagiri hospital, Bangalore. Int J Basic Clin Pharmacol 2019;8:2759-62. 